\title{
A new student-led dissection approach to the glenohumeral joint
}

\author{
Robert J. Leigh ${ }^{1}$, Deborah Merrick ${ }^{2}$ \\ ${ }^{1}$ School of Medicine, Faculty of Medicine and Health Sciences, University of Nottingham, United Kingdom \\ ${ }^{2}$ School of Life Sciences, Faculty of Medicine and Health Sciences, University of Nottingham, United Kingdom
}

\section{SUMMARY}

Modern day anatomy educators face many educational challenges associated with changes in curriculum, institutional reorganization and reduced teaching hours-all alongside criticism that medical students' anatomical knowledge at graduation is insufficient. At the University of Nottingham in the United Kingdom, a traditional approach to full body cadaveric dissection is carried out in the undergraduate medical curriculum, using dissection manuals based on long- published dissector guides. First-year medical students dissect the shoulder region in a superficial manner allowing good visualization of musculature and surrounding neurovascular structures, although observation of the internal joint is significantly limited. This study reports a student-led adaption to a novel dissection approach of the glenohumeral joint, which involves splitting the humeral head to expose the internal joint capsule in exceptional detail. The prosection generated was incorporated into an on-line teaching package for first-year medical students. Students' knowledge of the region was assessed before and after accessing the online teaching material, and results highlighted a significant improvement in anatomical knowledge after completion of the package ( $P$ $=0.013)$. First-year medical students who view

Corresponding author:

Dr. Deborah Merrick. School of Life Sciences, University of Nottingham

Medical School, Queen's Medical Centre, Nottingham, NG7 2UH,

United Kingdom. E-mail: deborah.merrick@nottingham.ac.uk the novel dissection also out-performed secondyear medical students who had experienced traditional teaching of this region $(P=0.002)$. This study has demonstrated that a novel dissection of the glenohumeral joint can provide educational benefit by increasing anatomical knowledge of the region. Furthermore, student-led innovations may act as a powerful means of achieving muchneeded reform in the field of musculoskeletal anatomy education.

Key words: Gross anatomy education Medical education - Undergraduate education Musculoskeletal medicine - Glenohumeral joint - Cadaveric dissection

\section{INTRODUCTION}

Future clinicians need a proficient understanding of core anatomy as a backbone of their clinical practice (Lazarus et al., 2012). In recent decades, the medical curriculum has seen a decrease in time devoted to a range of basic medical sciences, including anatomy, to allow for much wider teaching within modern medicine (McKeown et al., 2003; Turney, 2007; Rockarts et al., 2020). Alongside these implemented changes, there is growing concern by many newly qualified doctors and senior clinicians that graduates sim-

Submitted: November 8, 2021. Accepted: December 3, 2021 
ply do not possess sufficient anatomical knowledge for their first clinical placement (Waterson and Stewart, 2005; Fitzgerald et al., 2008). Deficits in medical students' knowledge (Day et al., 2007; Al-Nammari et al., 2015) and lack of confidence in performing and interpreting the findings of musculoskeletal examinations are often cited in the literature (Skelley et al., 2012; Peitzman and Cuddy, 2015). Further evidence suggests that the current approach to preclinical musculoskeletal medicine provides no improvement to clinical competency post-graduation (Khorsand et al. 2018). The deficit in the musculoskeletal field of teaching has been observed in institutions across the world, which has led to attempts at improvement by adaptation of the curriculum (Murphy et al., 2014; Hose et al., 2017). Curricular reform, via multidisciplinary collaboration, student-run musculoskeletal (MSK) clinic (McQuillan et al., 2017) and novel approaches to dissection (Hlavac et al., 2017; Cotofana et al., 2021) have been cited in the literature as potential routes to improve education in this field (Murphy et al., 2014). A solid foundation of musculoskeletal anatomy is clinically very important, as musculoskeletal disorders and complaints are commonly observed within the clinical setting (Huisstede et al., 2006: Buchbinder et al., 2013). It is therefore essential that medical students receive appropriate teaching of these regions, within the confines of the time allocated in the curriculum. The mode of teaching and its effectiveness is therefore an important consideration of all anatomy educators.

First-hand cadaveric dissection is often referred toasthegold standardforteachinganatomy, which, many would argue, has seen little development or change over many preceding decades, if not centuries (Elizondo-Omaña et al., 2005; Memon, 2018). Cadaveric dissection serves to provide a unique and authentic three-dimensional view of the organization of the human body, illustrating anatomical variation and pathology (often representative of the local population), alongside reinforcing compassion and respect (Konschake and Brenner, 2014; Dissabandara et al., 2015;). Although numerous reported benefits are associated with full body cadaveric dissection, many universities are moving away from this teaching practice, cited reasons including a shortage of qualified anatomists (Wilson et al., 2019), lack of cadaveric material (Chen etal., 2018) and the financial and time-consuming nature of the teaching modality (Patel et al., 2015; Estai and Bunt, 2016; Ghazanfar et al., 2018;). This, coupled with recent advancements in technological media to learn anatomy, has resulted in some medical schools' revision of their anatomical curricula with less emphasis, or completely without any emphasis at all, on the features of cadaveric dissection (Parker, 2002; Davis et al., 2014; Memon, 2018; Birbara et al., 2020). The improvement in technology, alongside the need to adapt teaching to the Covid-19 pandemic, means that online learning or a blended approach is now commonplace for anatomy teaching (Evans et al., 2020; Franchi, 2020; Pather et al., 2020). Recent findings suggest that these new approaches can provide students with greater knowledge of gross anatomy, provided there is sufficient student engagement (Green and Whitburn, 2016; Green et al., 2018).

The University of Nottingham in the United Kingdom (UK) runs an undergraduate-entry Medicine BMBS program where students experience 98 hours of gross anatomy teaching during their preclinical (years 1-3) training (Pratten et al., 2014). Teaching takes the form of lectures, workshops and practical cadaveric dissection classes that are largely based on the approach described in Hansen dissector (Hansen, 2002). Students carry out full body cadaveric dissection, alongside having access to pre-dissected (prosected) material, osteology specimens, a digital imaging library, anatomical models and on-line computer aided learning packages to help support their learning within the dissecting room (Turmezei et al., 2009). Assessment of gross anatomical knowledge forms the basis of an end-of-year Objective Structured Practical Examination, and application of this knowledge is incorporated into theory-based endof-year summative exams. The musculoskeletal gross anatomical component of the medical course is taught primarily in year 1 , and comprises a total of 28 teaching contact hours (7 one-hour lectures and 21 hours of dissection). This approach is 
consistent with other UK Medical Schools in both the delivery method and devoted teaching time (Gogalniceanu et al., 2009). A very small number of students have the chance to dissect again as part of a second-year anatomy optional module (8-10/300), or as part of a third-year dissertation project (14-16/300). As student enter the clinical phase of the medical course (years 4 and 5), they receive ad hoc informal musculoskeletal teaching within the clinical setting, although the exact amount of this teaching is difficult to determine and will vary widely. Formal teaching does occur in the final clinical year during their Musculoskeletal Disorders and Disability module.

At the University of Nottingham, the educational approach utilized in gross anatomy teaching is reevaluated annually. This ensures that the anatomical content and its delivery is clinically relevant and effective for teaching clinicians of the future (Leveritt et al., 2016; Marino et al., 2018). Students play an important role in this reevaluation process by identifying common anatomical difficulties before subsequently designing, implementing and evaluating new dissection protocols. This study presents an example of a shoulder dissection reevaluation, adapted from a study by Fabrizio et al. (2017), to be carried out by first-year medical students with limited dissection experience and within a short timeframe. The educational value and effectiveness of this approach are discussed. The findings suggest that there is real potential to empower medical students to help improve their own anatomy education, at a time when [arguably] reform of this age-old medical teaching is needed more than ever before.

\section{MATERIALS AND METHODS}

Undergraduate medical students at the University of Nottingham (UK) carry out an optional module during their second year. Students rank optional modules in order of preference and an algorithm is applied to provide allocations. "Advanced Anatomical Sciences" is one optional module available for a small number of medical students (8-10/300) each year led by an Anatomist. The aim of this module is for students to gain a greater insight into an anatomical region of interest. In doing so, students explore clinical relevance through the process of cadaveric dissection. The module incorporates lectures (2 hours), practical dissection classes (10 hours) and workshops (5 hours), all supported by the lead Anatomist. Students are asked to reflect on personal dissection experience, current dissection methodology (including Hansen, 2002; Tank, 2005; Clemente, 2007), clinical significance of the region and explore difficult concepts associated with the area of study. Students then design and implement a dissection approach based on their findings. Finally, they produce a portfolio in which they reflect on their experience leading their own dissection, in comparison to group dissections performed earlier in the medical course. Reflective discussion was emphasized as a key learning objective and marking criterion in the final portfolio produced in this module. Three elements of the module are assessed to provide a summative module mark; the quality of dissection/ prosection generated, an oral presentation and a reflective portfolio. One student's approach in this module led to the adaptation of a recently described novel dissection method of the glenohumeral joint (Fabrizio et al., 2017), which had only ever been performed by professional dissectors. The students' adaptation devised a method that could be performed by students/ novices, suggesting that the novel dissection method is suitable for introduction into medical school curriculum.

\section{Student adaptation of a novel dissection approach of the glenohumeral joint}

Dissector manuals routinely used by undergraduate medical students direct a superficial approach focusing mostly on preservation and identification of neuromuscular structures surrounding the glenohumeral joint (Zuckerman, 1981; Hansen, 2002; Tank, 2005; Clemente, 2007). Although this is a good approach to visualize the brachial plexus, musculature and superficial osteology, observation of internal joint structure is limited. A novel approach to the glenohumeral joint dissection detailed below (steps 1-3) allowed the internal joint capsule to be observed in detail, whilst maintaining the integrity 
to the head of the humerus and its associated musculature (approach adapted from Fabrizio et al., 2017).

1. Skin and subcutaneous fascia surrounding the upper two thirds of the arm was reflected, continuing superiorly to the furthest lateral projection of the clavicle. The anterior part of thedeltoid was reflected bycuttingits proximal attachment. Trapezius and infraspinatus fascia were removed, and the posterior part of the deltoid reflected by cutting its medial attachment (Fig. 1).

2. The proximal humerus was cut twice with an oscillating 16,000/min cast saw (CC4 cast saw system; de Soutter Medical Ltd., Buckinghamshire, UK). The first cut was a longitudinal cut along the shaft of the humerus. The cut extended along the lateral aspect of the proximal one third of the humerus, commencing anterior to the greater tubercle and posterior to the lesser tubercle of the humerus. The second cut, perpendicular to the first, extended posteriorly from the distal end of cut one (Fig. 2A). Care was taken to ensure that the cuts did not damage any nearby structures, including rotator cuff musculatures and tendon of the long head of the biceps muscle.

3. The head of the humerus was opened to view the internal structures using a $23 \mathrm{~mm}$ postmortem chisel (Surgical Holdings, Southend-on-Sea, UK) to view internal joint structures. The integrity of the muscles in this region was maintained throughout the dissection procedure (Fig. 2B). Further detailed dissection allowed the identification of the long head of biceps brachii tendon, glenoid labrum and the subscapularis tendon (Fig. 2C-D).

The novel glenohumeral joint dissection approach was successfully completed in its entirety by one second-year medical student.
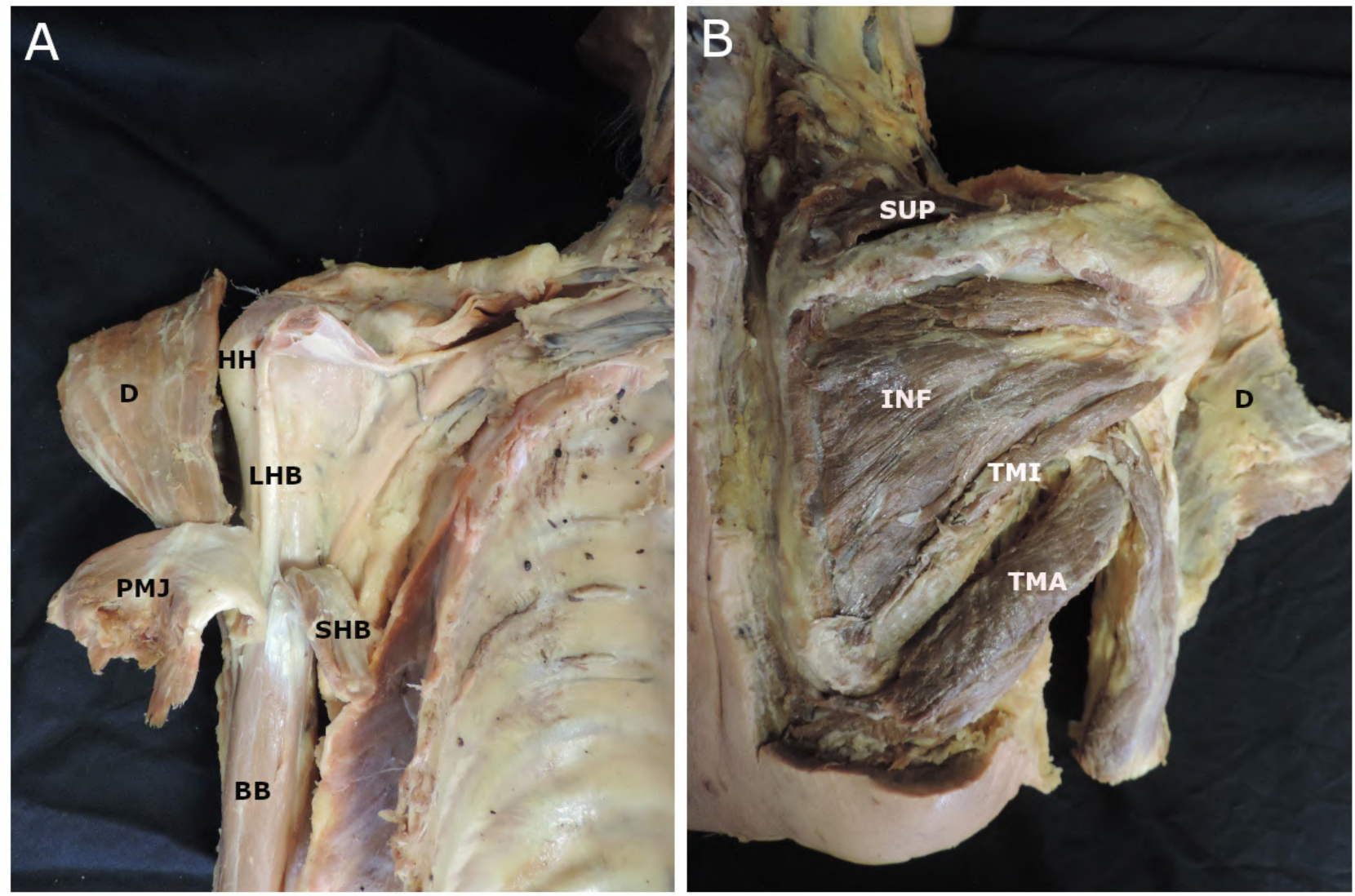

Fig. 1.- Standard undergraduate medical students dissection approach of the glenohumeral joint. A: Anterior view of proximal humerus with deltoid (D) and short head of biceps brachii reflected. B: Posterior view of the shoulder illustrating associated rotator cuff musculature. The dissection was carried out on an elderly female cadaver by the lead author within the anatomy suite (BB - biceps brachii, D - deltoid, HH - humeral head; INF infraspinatus, LHB - long head of biceps brachii; PMJ - pectoralis major, SHB - short head of biceps brachii, SUP - supraspinatus, TMA - teres major, TMI - teres minor). 
The generation of the prosection took 8 student dissection hours in total. This approach started with skin reflection, identification and preservation, where possible, of musculature and neurovascular structures surrounding the shoulder. The time taken incorporated meticulous dissection, detailed imaging and documentation of the dissection stages. The final stage of this novel prosection approach, which encompassed the splitting of the humeral head, took approximately 10 minutes (an anatomy technician helped stabilize and hold the prosection during this final stage). The cadaveric protocols carried out were in line with Human Tissue Act 2004 regulations, and carried out in a designated laboratory.

\section{On-line learning package to illustrate the novel dissection}

First-year medical students were then given the opportunity to view the new glenohumeral joint prosection on-line teaching package (it was
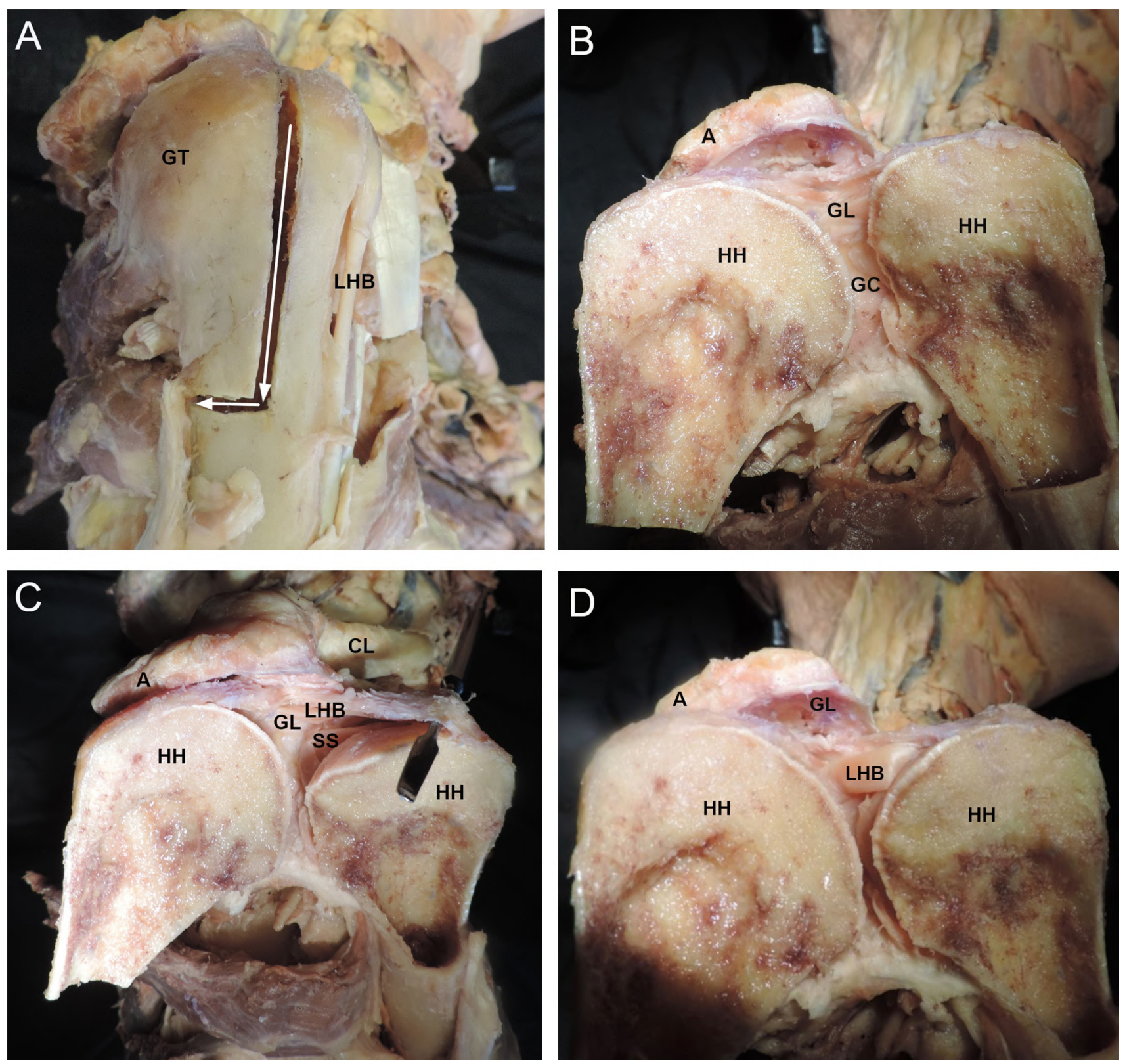

Fig. 2.- Novel undergraduate medical student dissection approach of the glenohumeral joint. A: Proximal humerus viewed from the lateral aspect highlighting the direction of saw cuts made. B: View of joint capsule upon initial opening. C-D: Joint capsule as viewed following minimal dissection of the region to highlight the long head of biceps brachii insertion into the glenoid labrum. The dissection was carried out on an elderly female cadaver by the lead author within the anatomy suite (A - acromion; CL - clavicle; GC - glenoid cavity; GL - glenoid labrum; GT - greater tubercle of humerus; HH - humeral head; LHB - long head of biceps brachii; SS - subscapularis muscle). 
initially planned that all students would view the prosection within the anatomy suite; however, due to the unprecedented impact of Covid-19, this was not feasible). The teaching package was created by a second-year medical student (author R.J.L.) using PowerPoint software, version 16.31 (Microsoft Corp., Redmond, WA) and made accessible to students via Moodle course management system, version 3.7.5 (Moodle, West Perth, WA, Australia), the University of Nottingham on-line teaching platform. Anatomical accuracy of the package was checked and verified by the lead Anatomist (author D.M.). The teaching package began with a five-minute introduction to the shoulder region, which consisted of commonly seen anatomical drawings and still images of shoulder anatomy, accompanied by audio to aid learning. The teaching package then introduced the methodology of the new dissection method, comparing and contrasting to standard dissection in the medical course. Still images/photographs (taken on a Panasonic Lumix DMC-G7 digital camera (Panasonic UK \& Ireland, Bracknell, UK) were used, which demonstrated the process of the novel dissection, accompanied by audio files describing method of dissection. This package took an average of 30 minutes to complete.

\section{Effectiveness of novel dissection approach (quantitative cohort analysis)}

A series of questions were designed by the authors to explore the first-year undergraduate medical students' knowledge of the glenohumeral joint, which were then verified by an additional anatomist for appropriate level and accuracy. Applying the principles of Bloom's taxonomy to the quizzes, the questions were identified to be aimed at knowledge, comprehension and application levels of learning deemed appropriate for first year undergraduate students (Bloom, 1956). Questions were piloted and validated with a cohort of second-year medical students $(n=122)$ who had already completed teaching, learning and assessment of this region in the previous academic year. The second-year students did not access the on-line teaching package; however, the pilot study allowed the series of questions to be grouped based on question type (cadaveric or non-cadaveric-based) and on difficulty levels. The questions were then randomly allocated to two comparable quizzes, each containing eight questions (herein named quiz A and quiz B; see Appendix A for examples of knowledge-based questions). First-year medical student completed quiz A prior to accessing the on-line package and quiz B following completion of the package. Quizzes were delivered in survey monkey (SNMK Inc., San Mateo, CA) and data extracted into Excel spreadsheet program, version 16.31 (Microsoft Corp., Redmond, WA). Quiz A was made available to all first-year medical students $(n=298)$ to complete on-line three weeks after they had been taught the anatomy of the glenohumeral joint through dissection following a standard dissection approach (outlined in Hansen, 2002). As the first- and second-year medical students were taught using the same dissection approach, Cronbach alpha and Kendall's Tau statistical tests were carried out to judge the consistency and validity of each cohort's performance on Quiz A (i.e., the students' performance prior to seeing the novel dissection).

All first-year medical students were encouraged to access the package and then complete a second quiz (quiz B). All elements of this study (on-line package and quizzes) were optional throughout and therefore students were able to choose their level of engagement. Ethical approval of this project was obtained by the School of Life Sciences Ethics Committee, University of Nottingham, UK (Ref no. C110320DM). A paired t-test was used to statistically compare results from quiz A and B. A paired t-test was also performed to statistically compare results between the pilot group (secondyear medical students) and first year medical students: this compared performance in quiz-A questions when neither cohort had seen the novel dissection, and in quiz-B questions when only the first-year medical students had seen the novel dissection (accessed teaching package).

\section{RESULTS}

The on-line teaching package presenting the novel glenohumeral joint prosection was accessed by 144 first-year medical students (48.3\% of year cohort) following staff making 
on-line announcements of its presence. Of the students who accessed the package, $22.2 \%(\mathrm{n}=$ 32) completed quiz $A$, and $18.1 \%(n=26)$ quiz $B$ between April-May 2020.

\section{Cohort performance before viewing novel dissection on-line package}

No statistical difference in overall initial quiz (A) performance was observed between firstand second-year medical students $(P=0.38$; Fig. $3)$. Both cohorts of students performed better on non-cadaveric questions (year $1,57.5 \% \pm 1.6 \mathrm{SD}$; year $2,34.2 \% \pm 4.4 \mathrm{SD}$ ) compared with questions requiring interpretation of cadaveric images (year 1, 31.3\% $\pm 18.7 \mathrm{SD}$; year $2,31.7 \% \pm 13.3$ $\mathrm{SD})$. However, the increased performance of both cohorts on non-cadaveric questions compared to cadaveric questions was insignificant $(P=$ 0.34). Cronbach's alpha statistical test showed high internal consistency (0.79) for quiz A, with Kendall's tau-b test showing an insignificant correlation $(0.57, P=0.064)$.

\section{Cohort performance after viewing novel dissection on-line package}

First-year medical students showed a statistically significant increase in the number of correct responses after completing the on-line package, compared with their initial quiz ( $\mathrm{p}=$ 0.013; Fig. 4). The mean score for students taking the initial quiz (A) before viewing the on-line teaching package was $40.3 \%$ ( $\pm 17.3 \mathrm{SD})$, whereas the mean score after viewing the resource (quiz B) was $76.0 \%( \pm 17.6 \mathrm{SD})$. First-year medical students' ability to correctly identify structures on images of cadaveric specimen increased from $31.3 \%$ ( $\pm 18.7 \mathrm{SD})$ to $76.3 \%$ ( $\pm 15.8 \mathrm{SD})$ following visualization of the novel glenohumeral joint prosection. A similar increase was observed for non-cadaveric questions without any associated imagery $(49.3 \% \pm 9.39 \mathrm{SD}$ to $75.8 \% \pm 19.6 \mathrm{SD})$. Looking at performance based on question type, after completing the on-line teaching package, students now scored equally well on cadaveric compared with non-cadaveric questions (76.3\% \pm 15.8 SD and $75.8 \% \pm 19.6$ SD respectively, $p$

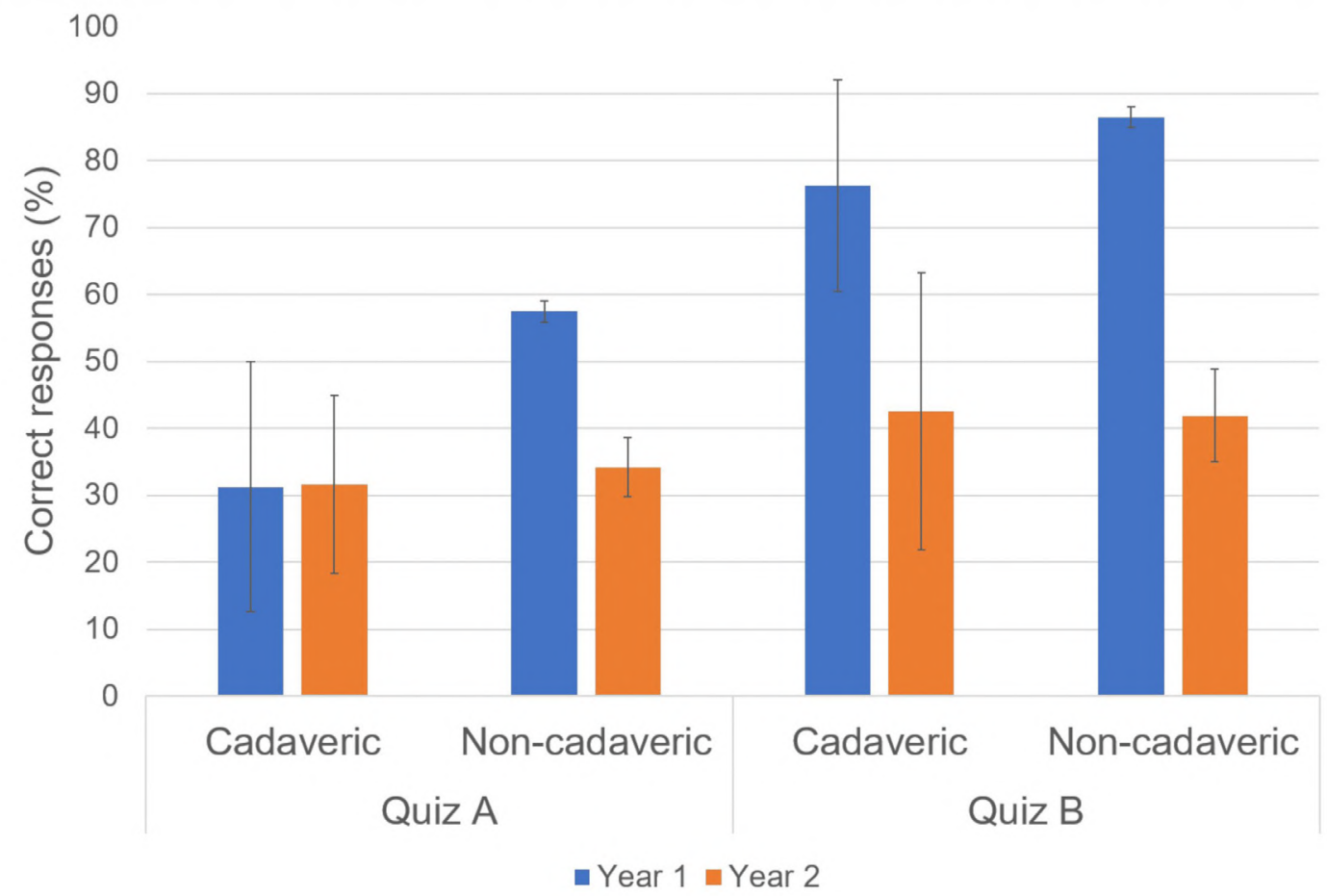

Fig. 3.- First-year and second-year undergraduate medical students' performance on a series of anatomical questions based around the shoulder region. Questions in each quiz were themed as being cadaveric or non-cadaveric knowledge-based questions. Quiz A relates to questions asked prior to first-year medical students viewing the novel prosection, quiz B relates to questions asked after first-year students viewed the on-line teaching package. Note the second-year medical students did not view the teaching package illustrating the novel glenohumeral dissection at any point during this study (error bars = standard deviation). 
$=0.15)$. Second-year students did not view the teaching package but did answer questions associated with the second quiz (quiz B). Across all question types, second-year medical students were outperformed by those first-year medical students who had viewed the on-line teaching package ( $P=0.002$; Fig. 3$)$.

\section{DISCUSSION}

Shoulder pain is a common and disabling complaint with a lifetime prevalence of up to 70\% (Luime et al., 2004); with glenohumeral joint disorders (e.g., problems associated with the subacromial bursa) being one of the most common causes of shoulder pain in primary care (Mitchell et al., 2005; Greenberg, 2014). Clinical diagnosis in primary care is principally achieved through careful history taking and physical examination. Therefore, clinical knowledge and experience are essential in accurate diagnosis and establishing the appropriate management (Mitchell et al., 2005; Artus et al., 2017). However, global data suggest that there is low confidence in primary healthcare practitioners' ability to diagnose and appropriately manage shoulder pain (Glazier et al., 1998; Loebenberg et al., 2006; Buchbinder et al., 2013). This, coupled with the growing evidence that musculoskeletal knowledge (Day et al., 2007; Al-Nammari et al., 2015), and confidence in applying this knowledge (Peitzman and Cuddy, 2015; Marino et al., 2018), is often inadequate in medical students, illustrates the importance of establishing optimal teaching of this region (Skelley et al., 2012). This study has shown how first-year medical students' performance improved on a series of cadaveric and non-cadaveric knowledgebased questions (an increase of $45.0 \%$ and $26.5 \%$ respectively) after viewing images of the novel glenohumeral joint dissection $(p=0.013)$. These students also out-performed second-year medical students who had been taught and assessed on this region of anatomy in the previous academic year, but who did not view the on-line teaching package $(p=0.002)$. These results suggest that a blended approach to anatomy teaching is effective and can provide students with greater knowledge. These results are in line with other published studies (Green and Whitburn, 2016; Green et al., 2018). Combining such approaches with exposure to a clinical setting may have optimal educational benefit (Newcomer et al., 2013; Sayma and Williams, 2016; Khorsand et al., 2018). Therefore, it will be important to establish where in the curriculum this teaching should ideally take place.

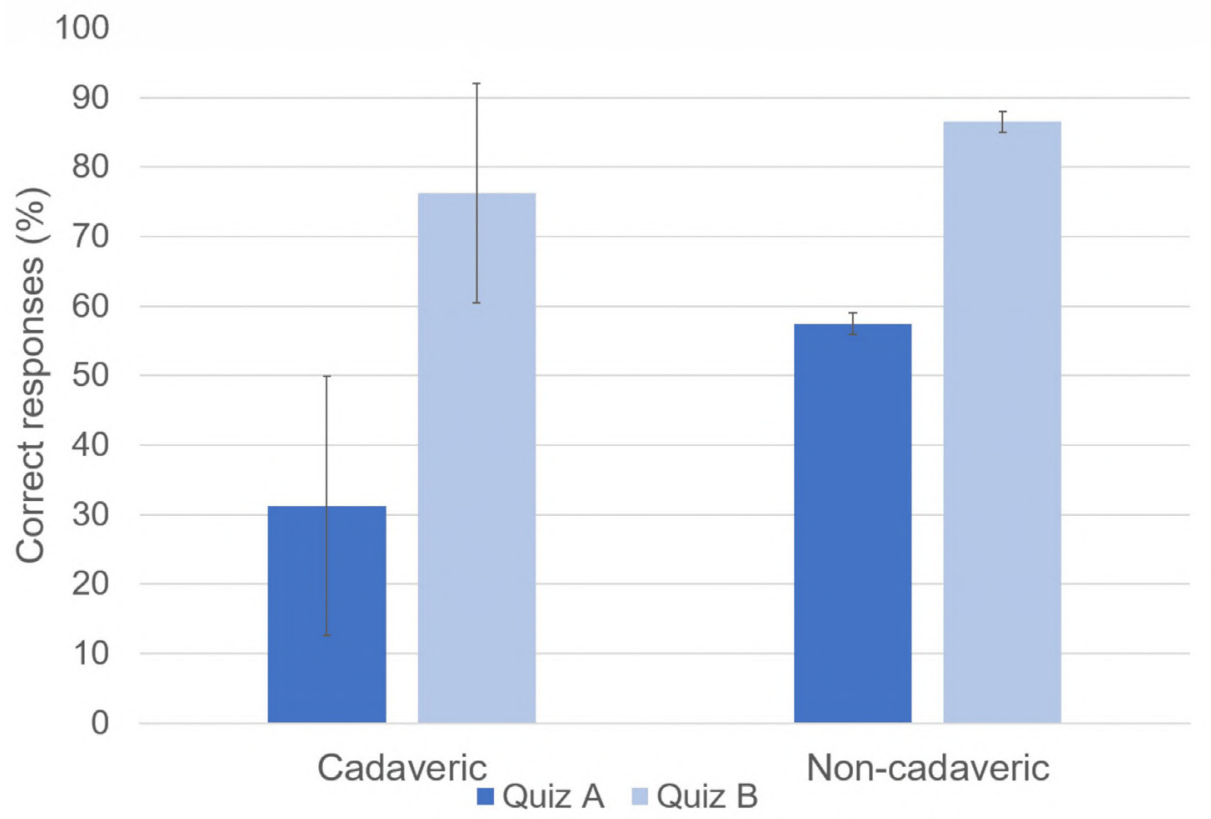

Fig. 4.- First-year undergraduate medical students' performance on a series of anatomical questions based around the shoulder region before (quiz A; $\mathrm{n}=32$ ) and after (quiz B; $\mathrm{n}=26$ ) viewing a novel prosection of the glenohumeral joint on-line. Questions in each quiz were themed as being cadaveric or non-cadaveric knowledge-based questions (error bars = standard deviation). 
There is a growing body of literature describing novel dissection approaches to a variety of different anatomical regions, including the orbit (Cotofana et al., 2006), knee (Clemente et al., 2009), brain (Hlavac et al., 2017) and sinoatrial node of the heart (Nooma et al., 2020). Many of these novel dissections have been carried out by skilled surgeons, anatomists, or postgraduate medical students with extensive dissection experience (Mattioli et al., 2017; Cotofana et al., 2021). If a novel dissection approach requires the skill and time of a clinician or anatomist to carry out, the impact it can have in a medical curriculum setting may be very limited. However, this study reports for the first time that a novel dissection of the glenohumeral joint can be carried out by a novice dissector using standard dissection tools, typically available to undergraduate students within practical dissection classes. This is being championed at the University of Nottingham (UK), and in this academic year (2021-22) the new glenohumeral dissection approach will be incorporated into all first-year student-led dissection classes. Finally, it is of note that the appraisal of the current dissection approaches and execution of the novel glenohumeral dissection approach were carried out within an optional module setting. Optional modules within a medical curriculum inherently have more autonomy and may serve as an opportunity to empower students to drive reform and make innovations (Novak et al., 2011; Cantwell et al., 2015; Georgetti et al., 2021).

\section{Limitations of the Study}

The internal consistency of the quiz (A) was found to be consistent with other classifications as "high/acceptable" (Tavakol and Dennick, 2011; Taber, 2018), and suggests that the quizzes were consistent in their ability to assess the same areas of knowledge in both first- and secondyear students. No relationship could be identified between performances on quiz (A) questions between first- and second-year medical students (as ascertained by Kendall's tau-b). However, this insignificance may be attributed to the small amount of data in this correlation, given that only quiz-A questions were included (quiz-B questions were excluded as, unlike first-year students, second-year students did not see the novel dissection when answering these questions). Just under half of the first-year medicine cohort (48.3\%) accessed the optional on-line resource, and only a proportion of these carried out the associated quizzes (18.1-22.2\%). The uptake may have been limited due to the fact that the end-ofyear Objective Structured Practical Examination was cancelled because of the restrictions imposed by the Covid-19 pandemic. Therefore, although only speculative, the cancelling of the gross anatomy practical exam may have influenced the time that students devoted to revising this discipline. This study utilized cohorts of medical students at the University of Nottingham (UK) through an unprecedented time where anatomy teaching was moved on-line in a rapid and tight timeframe. Therefore, it is acknowledged that findings from this study may not be generalized to other institutional settings and other student populations.

\section{CONCLUSIONS}

Medical students' knowledge of musculoskeletal anatomy is reported widely in the literature to be inadequate and not sufficient for clinical placement. This study looked at ways to utilize a novel student-led dissection approach to improve the knowledge of the glenohumeral joint in first-year medical students. Through creation of an anatomy blended on-line teaching package, students gained greater regional insight, illustrated by improved performance in knowledge-based questions. Novel cadaveric dissections are not a new concept, but novel approaches that can increase subject knowledge and be carried out by novice dissectors may have real educational benefit that is worthy of further exploration and, where successful, curriculum reform.

\section{ACKNOWLEDGEMENTS}

The authors sincerely thank those who donated their bodies to science so that anatomical research and teaching could be performed. Results from such research can potentially increase scientific knowledge and can improve patient 
care. Therefore, these donors and their families deserve our highest respect. The authors would also like to thank all of the Anatomy Suite staff at the University of Nottingham for help during this study. In particular, thanks to Miss Leia Boote and Miss Jo Lockley for their technical support during the final stages of prosection generation.

\section{NOTES ON CONTRIBUTORS}

ROBERT J. LEIGH, BMedSci., is a fourth-year undergraduate medical student in the School of Medicine, Faculty of Medicine and Health Sciences at the University of Nottingham, Nottingham, United Kingdom.

DEBORAH MERRICK, B.Sc., Ph.D., S.F.H.E.A., is an assistant professor of anatomy in the School of Life Sciences, Faculty of Medicine and Health Sciences at the University of Nottingham, Nottingham, United Kingdom. She teaches anatomy and embryology to pre-clinical medical students and is a senior tutor for medicine. Her research interests include student engagement and assessment within anatomical education and student wellbeing.

\section{REFERENCES}

AL-NAMMARI SS, PENGAS I, ASOPA V, JAWAD A, RAFFERTY M, RAMACHANDRAN M (2015) The inadequacy of musculoskeletal knowledge in graduating medical students in the United Kingdom. $J$ Bone Joint Surg Am, 97: e36.

ARTUS M, VAN DER WINDT DA, AFOLABI EK, BUCHBINDER R, CHESTERTON LS, HALL A, RODDY E, FOSTER NE (2017) Management of shoulder pain by UK general practitioners (GPs): a national survey. BMJ Open, 7: e015711.

BIRBARA NS, SAMMUT C, PATHER N (2020) Virtual reality in anatomy: A pilot study evaluating different delivery modalities. Anat Sci Educ, 13: 445-457.

BLOOM BS (1956) Taxonomy of Educational Objectives: The Classification of Educational Goals. Handbook 1: Cognitive Domain. $1^{\text {st }} \mathrm{ed}$. David McKay Co, Inc, New York, pp 201.

BUCHBINDER R, STAPLES MP, SHANAHAN EM, ROOS JF (2013) General practitioner management of shoulder pain in comparison with rheumatologist expectation of care and best evidence: an Australian national survey. PLoS One, 8: e61243.

CANTWELL S, BONADURER GF, PAWLINA W, LACHMAN (2015) Near-peer driven dissection selective: A primer to the medical school anatomy course. Clin Anat, 28: 985-993.

CHEN D, ZHANG Q, DENG J, CAI Y, HUANG J, LI F, XIONG K (2018) A shortage of cadavers: The predicament of regional anatomy education in mainland China. Anat Sci Educ, 11: 397-402.

CLEMENTE CD (2007) Clemente's Anatomy Dissector. $2^{\text {nd }} e d$. Lippincott, Williams and Wilkins, Baltimore, MA, pp 65-68.

CLEMENTE FR, FABRIZIO PA, SHUMAKER M (2009) A novel approach to the dissection of the human knee. Anat Sci Educ, 2: 41-46.

COTOFANA S, GAVRIL DL, FRANK K, SCHENCK TL, PAWLINA W, LACHMAN N (2021) Revisit, reform, and redesign: A novel dissection approach for demonstrating anatomy of the orbit for continuing professional development education. Anat Sci Educ, 14: 505-512.

DAY CS, YEH AC, FRANKO O, RAMIREZ M, KRUPAT E (2007) Musculoskeletal medicine: An assessment of the attitudes and knowledge of medical students at Harvard Medical School. Acad Med, 82: 452-457.
DAVIS CR, BATES AS, ELLIS H, ROBERTS AM (2014) Human anatomy: Let the students tell us how to teach. Anat Sci Educ, 7: 262-272.

DISSABANDARA LO, NIRTHANAN SN, KHOO TK, TEDMAN R (2015) Role of cadaveric dissections in modern medical curricula: a study on student perceptions. Anat Cell Biol, 48: 205-212.

ELIZONDO-OMAÑA RE, GUZMÁN-LÓPEZ S, GARCÍA-RODRÍGUEZ MA (2005) Dissection as a teaching tool: Past, present, and future. Anat Rec, 285B: 11-15.

ESTAI M, BUNT S (2016) Best teaching practices in anatomy education: A critical review. Ann Anat, 208: 151-157.

EVANS D, BAY BH, WILSON TD, SMITH CF, LACHMAN N, PAWLINA W (2020) Going virtual to support Anatomy Education: A STOPGAP in the midst of the Covid-19 pandemic. Anat Sci Educ, 13: 279-283.

FABRIZIO P, TOPPING D, WOLFE K (2017) Glenohumeral joint dissection: A new protocol. Anatomy, 11: 37-41.

FITZGERALD JE, WHITE MJ, TANG SW, MAXWELL-ARMSTRONG CA, JAMES DK (2008) Are we teaching sufficient anatomy at medical school? The opinions of newly qualified doctors. Clin Anat, 21: 718-724.

FRANCHI T (2020) The impact of the Covid-19 pandemic on current Anatomy Education and future careers: a student's perspective. Anat Sci Educ, 13: 312-315.

GEORGETTI LJ, SIMS AC, FOCHT, ELCOCK JN, NIXON-CAVE K, AMABILE AH (2021) Participation in an advanced anatomy capstone project facilities student involvement in the development of an instructional tool for novel dissection. Educ Res Int, 2021: 6681994.

GHAZANFAR H, RASHID S, HUSSAIN A, GHAZANFAR M, GHAZANFAR A, JAVAID A (2018) Cadaveric dissection a thing of the past? The insight of consultants, fellows, and residents. Cureus, 10: e2418.

GLAZIER RH, DALBY DM, BADLEY EM, HAWKER GA, BELL MJ, BUCHBINDER, LINEKER SC (1998) Management of common musculoskeletal problems: a survey of Ontario primary care physicians. CMAJ, 158: 1037-1040.

GOGALNICEANU P, O'CONNOR EF, RAFTERY A (2009) Undergraduate anatomy teaching in the UK. Bull Roy Coll Surg Engl, 91: 102-106.

GREEN RA, WHITBURN LY (2016) Impact of introduction of blended learning in gross anatomy on student outcomes. Anat Sci Educ, 9: 422-430.

GREEN RA, WHITBURN LY, ZACHARIAS A, BYRNE G, HUGHES DL (2018) The relationship between student engagement with online content and achievement in a blended learning anatomy course. Anat Sci Educ, 11: 471-477.

HANSEN JT (2002) Essential Anatomy Dissector: following Grant's method. $2^{\text {nd }}$ ed. Lippincott, Williams \& Wilkins, Philadelphia, PA, pp 224.

HLAVAC RJ, KLAUS R, BETTS K, SMITH SM, STABIO ME (2017) Novel dissection of the central nervous system to bridge gross anatomy and neuroscience for an integrated medical curriculum. Anat Sci Educ, 11: 185-195.

HOSE MK, FONTANESI J, WOYTOWITZ M, JARRIN D, QUAN A (2017) Competency based clinical shoulder examination training improves physical exam, confidence, and knowledge in common shoulder conditions. J Gen Intern Med, 32: 1261-1265.

HUISSTEDE BM, BIERMA-ZEINSTRA SM, KOES BW, VERHAAR JA (2006) Incidence and prevalence of upper-extremity musculoskeletal disorders. A systematic appraisal of the literature. BMC Musculoskelet Disord, 7: 7.

KHORSAND D, KHWAJA A, SCHMALE GA (2018) Early musculoskeletal classroom education confers little advantage to medical student knowledge and competency in the absence of clinical experiences: A retrospective comparison study. BMC Med Educ, 18: 46.

KONSCHAKE M, BRENNER E (2014) “Mors auxilium vitae" - Causes of death of body donors in an Austrian anatomical department. Ann Anat, 196: 387-393. 
LAZARUS MD, CHINCHILLI VM, LEONG SL, KAUFFMAN GL (2012) Perceptions of anatomy: critical components in clinical setting. Anat Sci Educ, 5: 187-199.

LEVERITT S, MCKNIGHT G, EDWARDS K, PRATTEN M, MERRICK D (2016) What anatomy is clinically useful and when should we be teaching it? Anat Sci Educ, 9: 468-745.

LOEBENBERG MI, ROSEN JE, ISHAK C, JAZAWI LM, ZUCKERMAN JD (2006) A survey of decision-making processes in the treatment of common shoulder ailments among primary care physicians. Bull Hosp Jt Dis, 63: 137-144.

LUIME JJ, KOES BW, HENDRIKSEN IJ, BURDORF A, VERHAGEN AP, MIEDEMA HS, VERHAAR JA (2004) Prevalence and incidence of shoulder pain in the general population; A systematic review. Scand $J$ Rheumatol, 33: 73-81.

MARINO K, MERRICK D, EDWARDS K, PRATTEN M (2018) Musculoskeletal radiology teaching at a UK medical school: Do we need to improve? Anat Sci Educ, 12: 257-263.

MATTIOLO F, PRESUTTI L, CAVERSACCIO, BONALI, ANSCHUETZ L (2017) Novel dissection station for endolaryngeal microsurgery and laser surgery: Development and dissection course experience. Otolaryngol Head Neck Surg, 156: 1136-1141.

MCKEOWN PP, HEYLINGS DJ, STEVENSON M, MCKELVEY KJ, NIXON JR, MCCLUSKEY DR (2003) The impact of curricular change on medical students' knowledge of anatomy. Med Educ, 37: 954-961.

MCQUILLAN T, WILCOX-FOGEL N, KRAUS E, LADD A, FREDERICSON $M$ (2017) Integrating musculoskeletal education and patient care at medical student-run free clinics. PM R, 9: 1117-1121.

MEMON I (2018) Cadaver dissection is obsolete in medical training! A misinterpreted notion. Med Princ Pract, 27: 201-210.

MITCHELL C, ADEBAJO A, HAY E, CARR A (2005) Shoulder pain: Diagnosis and management in primary care. BMJ, 331: 1124-1128.

MURPHY RF, LAPORTE DM, WADEY VM, AMERICAN ACADEMY OF ORTHOPAEDIC SURGEONS ORTHOPAEDIC EDUCATION STUDY GROUP (2014) Musculoskeletal education in medical school: Deficits in knowledge and strategies for improvement. J Bone Joint Surg Am, 96: 2009-2014.

NEWCOMER KL, LASKOWSKI ER, GRANDE JP, DYRBYE LN (2013) The physiatrists' crucial role in the development and implementation of a longitudinal musculoskeletal physical examination curriculum in a medical school. Am J Phys Med Rehabil, 92: 84-89.

NOOMA K, SAGA T, IWANAGA J, TABIRA Y, WATANABE K, TUBBS RS, YAMAKI K (2020) A novel method with which to visualize the human sinuatrial node: Application for a better understanding of the gross anatomy of this part of the conduction system. Clin Anat, 33: 232-236.

NOVAK S, QUINN M, CANAN T, METTEN S, WISCO JJ, WIMMERS PF, UIJTDEHAAGE S (2011) A new approach to how to teach: medical students as instructional designers. Med Educ Online, 16: 7525.

PARKER LM (2002) Anatomical dissection: Why are we cutting it out? Dissection in undergraduate teaching. ANZ J Surg, 72: 910-912.

PATEL SB, MAURO D, FENN J, SHARKEY DR, JONES C (2015) Is dissection the only way to learn anatomy? Thoughts from students at a non-dissecting based medical school. Perspect Med Educ, 4: 259-260.

PATHER N, BLYTH P, CHAPMAN JA, DAYAL MR, FLACK N, FOGG QA, GREEN RA, HULME AK, JOHNSON IP, MEYER AJ, MORLEY JW, SHORTLAND PJ, ŠTRKALJ G, ŠTRKALJ M, VALTER K, WEBB AL, WOODLEY SJ, LAZARUS MD (2020) Forced disruption of anatomy education in Australia and New Zealand: An acute response to the Covid- 19 pandemic. Anat Sci Educ, 13: 284-300.

PEITZMAN SJ, CUDDY MM (2015) Performance in physical examination on the USMLE Step 2 Clinical Skills Examination. Acad Med, 90: 209-213.
PRATTEN MK, MERRICK D, BURR SA (2014) Group in-course assessment promotes cooperative learning and increases performance. Anat Sci Educ, 7: 224-233.

ROCKARTS J, BREWER, DELUCE D, SHALI A, MOHIALDIN V, WAINMAN B (2020) National survey on Canadian undergraduate medical programs: The decline of the anatomical sciences in Canadian medical education. Anat Sci Educ, 13: 381-389.

SAYMA M, WILLIAMS HR (2016) A new method for teaching physical examination to junior medical students. Adv Med Educ Pract, 7: 91-97.

SKELLEY NW, TANAKA MJ, SKELLEY LM, LAPORTE DM (2012) Medical student musculoskeletal education: An institutional survey. $J$ Bone Joint Surg Am, 94: e146.

TABER KS (2018) The use of Cronbach's alpha when developing and reporting research instruments in science education. Res Sci Educ, 48: 1273-1296.

TANK PW (2005) Grant's Dissector. $15^{\text {th }}$ ed. Lippincott, Williams \& Wilkins, Baltimore, MD, pp 57-60.

TAVAKOL M, DENNICK R (2011) Making sense of Cronbach's alpha. Int J Med Educ, 2: 53-55.

TURMEZEI TM, TAM M, LOUGHNA S (2009) A survey of medical students on the impact of a new digital imaging library in the dissection room. Clin Anat, 22: 761-769.

TURNEY BW (2007) Anatomy in a modern medical curriculum. Ann Roy Coll Surg Engl, 89: 104-107.

WATERSON SW, STEWART IJ (2005) Survey of clinicians' attitudes to the anatomical teaching and knowledge of medical students. Clin Anat, 18: $380-384$

WILSON AB, NOTEBAERT A, SCHAEFER A, MOXHAM BJ, STEPHENS A, MUELLER C, LAZARUS MD, KATRIKH AZ, BROOKS WS (2019) A look at the anatomy educator job market: Anatomists remain in short supply. Anat Sci Educ, 13: 91-101.

ZUCKERMAN SB (1981) A New System of Anatomy, a Dissector's Guide and Atlas. $2^{\text {nd }}$ ed. Oxford University Press, Inc, Oxford, UK, pp 135-140. 